\title{
O EMERGIR DAS REVISTAS DE MODA: A REVISTA HAPPY WOMAN: UM ESTUDO DE CASO
}

\author{
Rosa Maria Vasconcelos ${ }^{1}$, Maria Gabriela Gama ${ }^{2}$, Ana Catarina Pires ${ }^{3}$
}

\begin{abstract}
Nowadays the fashion communication emerges in another support different from the printed one, namely the internet. Spite this new way of communication there is still a market for the fashion journals. In 2006 a new journal appears in Portugal- "Happy Woman"-. The aim of this work was to determine if "Happy Woman" journal communicate a fashion message among their readers. In order to achieved the objective purposed a survey was carried out among fashion and communication students The data analysis leads us to conclude that $82 \%$ of the inquiries considered that "Happy Woman" journal has a good fashion communication message and the fashion students are the ones that mainly read this journal read.
\end{abstract}

Index Terms - Happy Woman, a fashion message, journal

\section{INTRODUÇÃO}

Durante muito tempo, o discurso sobre a beleza da mulher era obra, por exemplo, de poetas e de romancistas, "com a expansão da imprensa feminina de grande tiragem surge uma nova maneira de falar da aparência feminina" [1]. Façamos de um modo sucinto uma pequena viagem pela história da imprensa feminina. Apesar das publicações de moda serem mais antigas centramo-nos apenas no século XIX e no século XX.

Em 1867, surgiu nos Estados Unidos, a revista mais antiga de moda, a Harper's Bazaar, inicialmente em forma de folhetim. Seguiram-se a McCall's Magazine, em 1870, o Ladies Home Journal, em 1883, o Le Petit Écho de la Mode, em 1879, e a Revista Vogue, em 1892. Nos Estados Unidos, a Revista Vogue tem, desde a sua origem, uma matriz diferenciada da matriz europeia. Isto é, era uma publicação que acompanhava o dia-a-dia imponente de uma restrita elite noviorquina, e ao mesmo tempo, estava em sintonia com o universo da alta-costura parisiense. Uma imagem de glamour, sofisticação e de bom gosto, vai acompanhá-la até aos dias hoje. A Revista Harper's Bazaar seguiu uma trajetória diferente da Vogue no tipo de abordagem aos temas e aos interlocutores em que apostou.

Quanto ao sistema de distribuição das publicações americanos já desde 1869 que as Revistas passaram a ser vendidas em lojas comerciais e livrarias, libertando-se da dependência do correio [2]. Estas transformações foram significativas já que possibilitou a entrada a públicos diferenciados.

As primeiras reproduções de fotografias de moda surgem em 1892, em La Mode Pratique, incidindo apenas sobre conselhos acerca do vestuário. Le Jardin de Modes nasceu em 1918, e foi a primeira revista a aliar a temática da moda com o desenho, a decoração, as artes e as tendências. A Revista Modes et Travaux surgiu em 1919.

Entre a primeira e a segunda Guerra Mundial, a imprensa feminina desenvolve-se convergindo, cada vez mais, para os mais variados públicos. Em 1937, é lançado o semanário Marie Claire, inspirado nos jornais de matriz americana, visando democratizar as ferramentas de sedução ao difundir uma filosofia otimista e consumista da beleza, chegando a um público cada vez mais vasto, com um preço acessível. Nasce, assim, a "Vogue dos pobres" [1;3].

O desenvolvimento da imprensa no século XIX, em Paris e em Londres está muito ligada ao modo como estas cidades viviam a moda: Paris como o berço da alta-costura e Inglaterra pelo seu corte singular da alfaiataria masculina. Não podemos deixar de mencionar todas as evoluções tecnológicas de então que fizeram com que Paris e Londres funcionassem como arquétipos, como difusores de estilos; geradoras de paradigmas que ora abonam ora censuram em matéria e vestir.

De 1900 a 1920, por uma questão de moralidade, as alusões concernentes à maquilhagem são escassas e a publicidade a produtos de beleza é moderada. A partir do século $\mathrm{XX}$, as publicações femininas tornaram-se nas principais irradiadoras de uma panóplia de cuidados estéticos, emergindo uma nova retórica que une beleza e consumo, num estilo incisivo, acompanhado de imagens que marcam a diferença da imprensa feminina.

Assim, as revistas femininas foram encaminhando-se para as massas, transformaram-se nas principais difusoras de uma panóplia de cuidados estéticos, surgindo uma nova retórica que conjuga beleza e consumo, num estilo direto e vivo, ladeado de imagens que marcam a diferença da imprensa feminina. A imprensa feminina e a publicidade trabalham no mesmo sentido. "A partir dos anos 20, nos Estados Unidos, a publicidade esforça-se por modificar os hábitos femininos tradicionais, por erradicar os preconceitos que constituem obstáculo ao reino do consumo" [1].

\footnotetext{
${ }^{1}$ Rosa Maria Vasconcelos, Departamento de Engenharia Têxtil, Escola de Engenharia, Campus de Azurém, Universidade do Minho, 4800-058 Guimarães, Portugal, rosa@det.uminho.pt.

${ }_{2}^{2}$ Maria Gabriela Gama, Instituto de Ciências Sociais, Departamento de Ciências da Comunicação, Campus de Gualtar, 4710-057 Braga, Portugal, mgama @ics.uminho.pt

${ }_{3}^{3}$ Ana Catarina Pires, Mestre em Design de Comunicação de Moda da Escola de Engenharia da Universidade do Minho
} 
Esta época marca uma viragem na história da imprensa feminina que incita as mulheres a tudo fazerem para engrandecer o seu charme. Na linha de Lipovestsky passa a haver uma disseminação "das informações estéticas, valorização social dos cuidados corporais, voluntarismo das mensagens, são todos eles dispositivos que edificam a era democrática do belo sexo" [1]. Com todos estes mecanismos, "deixa de haver desculpa para a fealdade, e qualquer mulher consegue oferecer uma imagem sedutora de si mesma" [1].

Enquanto Lipovestsky olha para as publicações de moda como um “ (...) um vetor de personalização e de autoapropriarão estética" [1], Naomi Wolf é crítica e afastase da posição do autor. No seu livro, How images of beauty are used against women, publicado em 1991, afirma que as revistas de moda são um campo onde se joga um conjunto de imposições. Para a autora, a relação das leitoras com as revistas é “ (...) uma relação emocional, crédula, defensiva e desigual: "o elo que une as leitoras às suas revistas, o grande cordão umbilical, como alguns o chamam, a confiança" [4]. Ainda segundo a autora, o que está em causa é o modo como estas publicações difundem o culto do belo corpo. Perante os anúncios publicitários, por exemplo, vemos como no corpo da moda domina uma reprodução, uma multiplicidade de estilos, sem dúvida, mas um só corpo, um belo corpo. Sabemos que no “(...) passado, em nome da fé, o corpo era reduzido à expressão de subversão, mais tarde veio a transformar-se em espaço de punição, isto é, trata-se de castigar um corpo que nunca atinge a perfeição" [5]. Um corpo que precisa de ser trabalhado, malhado rumo à perfeição. Nunca se é suficientemente magro ou suficientemente belo; nunca se está à "altura". Nesta linha de pensamento, face a um tempo que privilegia o belo corpo associado à performance, à aquiescência social, trabalhado "sob a moral da boa forma, surge como marca indicativa de certa virtude superior daquele que o possui" [6].

Quando se observa as páginas das revistas é quase inquestionável que não se sinta uma dose de insegurança face aos modelos com corpos perfeitos. Mesmo sabendo que o Photoshop é uma ferramenta indispensável no retoque das imagens; mesmo intuindo que a beleza está à distância de um clique no mouse, que é uma perfeição fabricada, as revistas difundem arquétipos o que explica que muitas mulheres anseiam por se parecerem com um corpo que está para além dos corpos reais.

O corpo converteu-se numa substância imperfeita, incompleta, um rascunho a ser corrigido. Isto é, jamais "um corpo é deveras perfeito ou suficientemente belo. Está em causa punir um corpo imperfeito que não corresponde ao arquétipo ideal" [7]. Isto pode implicar uma desarrumação das suas escalas mentais. De facto, em simultaneidade com o pensamento de Baudrillard [8], sabemos que a moda "brinca" indiscriminadamente com os opostos, (...) com o moral e o imoral. Só não consegue jogar com o gordo e com o magro. Surge aqui uma espécie de limite absoluto". Tal como afirma, Buitoni: "A moda impulsiona a imprensa feminina e por ela é impulsionada" [9].

Naomi Wolf afirma que a relação de algumas mulheres com as revistas é a mesma que se joga na relação com um "clube desportivo" que é marcada pela confiança, segurança e, sendo assim, é discutível "ler uma revista com um olhar crítico para vermos até que ponto os investimentos publicitários influenciam as matérias" [4]. Um aspeto relevante a considerar é que as revistas têm um duplo papel, ou seja, por um lado encantar os seus leitores, e por outro lado, satisfizer os anunciantes. Sem estes as revistas não sobreviviam, daí a sua dependência. Ou seja, a "sua principal fonte de lucro é a publicidade, portanto, o conteúdo deve complementar e reforçar a publicidade" [10]. O número de fotografias, de anúncios, de imagens que veiculam um estilo de corpo tende a fomentar um desejo muitas vezes silencioso, mas irrefreável pela aquisição de determinados produtos de beleza, ou seja, a “(...) procura da beleza refuta toda a inércia" [7].

É claro que lemos uma revista de moda como um todo; um discurso transparente sobre todas as questões que interessam as mulheres; o que está in e o que está out; o que usar para favorecer e o que é proibitivo; o que engorda e o que emagrece; quais os cuidados para ter um corpo esbelto. Se por um lado, sabemos que as revistas de moda abordam temáticas que interessam as suas leitoras os seus leitores, “(...) levando em consideração [os] seus desejos e expectativas, expressando [as] suas esperanças e preocupações" [11]. Por outro lado, (...) têm sentimentos ambivalentes quanto ao prazer mesclado com uma ansiedade que essas revistas (...) proporcionam" [4].

Para Roland Barthes, encontramos na roupa uma tripla dimensão, ou seja, a roupa enquanto peça que vestimos; é palpável, a roupa enquanto imagem que observamos através das revistas, por exemplo, e a roupa caligrafada. Centremonos apenas, no registo da roupa/imagem e na roupa/escrita. De facto, na ótica de Roland Barthes, quer o roupa/imagem, quer a roupa/escrita apontam em princípio para "a mesma realidade, mas não têm a mesma estrutura, porque não são feitos dos mesmos materiais. Num os materiais são formas, linhas, superfícies, cores, e a relação é espacial; no outro, são palavras, e a relação é, se não lógica, pelo menos sintática. A primeira estrutura é plástica, e a segunda é verbal" [12].

Tal como defende o autor, [12] as publicações de moda regem-se através de narrativas onde a imagem e texto são ajustados de modo a difundir mensagens incisivas que determinam os arquétipos a serem são seguidos. Assim, a combinação perfeita de imagem e texto ilustram o poder que este tipo de publicações tem sobre o universo feminino.

A grande questão não está relacionada como a adesão ou não às cirurgias estéticas, com a compra ou não de peças de roupa em tendência, com a aquisição ou não de produtos de beleza de última geração, o problema está, por exemplo, "quando as mulheres sentem, que sem o arsenal de cosméticos se sentem invisíveis" [4]. Em sintonia com o 
pensamento da autora, quanto mais informadas estiveram as leitoras; quanto mais sentido crítico tiveram as mulheres “ mais aproveitariam o que houvesse de bom e rejeitariam o que o que consideravam pernicioso" [4].

Defendemos que através deste tipo de publicações se estabelecem vínculos, fomentam-se relações de partilha entre editores e eleitores, constroem-se identidades, cultivam-se relações. Assim, enfatiza-se que as revistas criam com através dos seus leitores “(...) uma relação renovada a cada edição. (...) Uma relação íntima e envolvente" [11]. Assim, não é em vão que os leitores “ (...) gostam de andar abraçados às suas revistas ou de andar com elas à mostra, para que todos vejam que eles pertencem a este ou àquele grupo" [13]. Mas porquê? Precisamente porque adquirir um determinado tipo de publicação de moda como por exemplo, a Harper's Bazaar, a Fashion book, a Vanity Fair ou a Vogue é comprar um estilo de vida; é adquirir cultura; é aprender a ter atitude para a vida; é, em última instância, pertencer à esfera de uma determinada tribo.

\section{A REVISTA HAPPY WOMAN: UM ESTUDO DE CASO}

A revista HAPPY Woman é uma publicação nacional e, apesar de estar inserida no target feminina/moda, não se pode afastar a hipótese de que o universo masculino não leia este tipo de publicações. À semelhança deste tipo de publicações, os temas a abordados são multifacetados. O tema central deste estudo incidiu sobre uma Revista de moda, a HAPPY Woman, uma publicação de âmbito nacional com a qual estamos familiarizados. Esta escolha justificou-se em virtude de não haver nenhum estudo sobre a mesma. O objetivo principal passou por compreender se a HAPPY Woman transmitia aos seus leitores uma mensagem de moda, entendendo-se como mensagem de moda, os conteúdos abordados pela revista.

Através da análise efetuada pretendeu-se determinar se os conteúdos de moda se destacam em relação aos outros conteúdos abordados na Revista HAPPY Woman. A pesquisa foi efetuada com alunos do curso de Design e Marketing de Moda da Universidade do Minho e os alunos do curso de Comunicação do Instituto Superior da Maia (ISMAI), e teve o intuito de perceber se, na opinião destes leitores concretos a mensagem que a revista transmitia seria maioritariamente de moda. Isto é, se no fim da leitura e de folhear as mais diversas páginas a mensagem que se destacava em detrimento das outras seria a de moda. Se os conteúdos de moda assumem um papel de destaque na revista.

Quanto à aplicação do inquérito, este teve a duração de um mês, decorreu no mês de junho de 2010 e foi realizada nas salas de aula. $\mathrm{O}$ conjunto de perguntas que compõem o questionário foram pensadas tendo sempre em conta as hipóteses do estudo, com o objetivo de obter dados que permitissem testar adequadamente essas mesmas hipóteses.

\section{ANÁlise e DiscuSSÃo de RESUltados}

Da amostra total do estudo consideraram-se 130 respostas válidas compostas por alunos de Comunicação (59\%) e alunos de Design de Moda (41\%). No que diz respeito à idade, os inquiridos situam-se na faixa etária dos 21 aos 30 anos (60\%). Quanto ao género, (70\%) são do sexo feminino e os restantes $30 \%$ são do sexo masculino.

Quando questionados se são ou não são leitores da HAPPY Woman apenas 44\% da amostra respondeu que sim. Analisando os inquiridos que leem a revista, verifica-se que a maior parte é estudante de moda. Dado existir um número significativo de não leitores optou-se por dividir a amostra e sua análise. Os "não leitores" da publicação em estudo assumem um grande destaque. Ou seja, representam $56 \%$ da amostra; são indivíduos que se situam na faixa etária entre os 21 e os 30 anos $(58 \%)$ e, no género a percentagem existente é semelhante (37\%) do sexo feminino e (36\%) do sexo masculino. Quanto à formação, 70\% dos "não leitores" da HAPPY Woman são alunos de Comunicação e $30 \%$ alunos de Moda. No entanto, quando questionados sobre a leitura de outras revistas de moda, a percentagem também é significativa, isto é, 63\% respondeu que não lê outro tipo de publicações deste género, embora os restantes $37 \%$ refiram a Revista Vogue, como leitura preferencial.

Os leitores da HAPPY Woman têm idades compreendidas entre os 21 e os 30 anos, são maioritariamente do sexo feminino (95\%) e os estudantes de moda $(54 \%)$ são os que mais leem a publicação nacional. Quanto ao modo como tiveram conhecimento desta publicação, (63\%) referiu que foi através dos quiosques. Quanto à frequência de leitura da mesma, (51\%) dos inquiridos lê entre 1 e 3 anos, (39\%), lê entre 3 a 6 vezes por ano e $(39 \%)$ entre 6 e 9 vezes por ano. Relativamente à questão sobre o que leva os estudantes de moda e de comunicação a ler a Revista HAPPY Woman, (53\%) referiram que é a diversidade dos conteúdos. Porém, $90 \%$ dos inquiridos são igualmente consumidores de outras revistas femininas/moda, como a Revista VOGUE (60\%) seguida da Cosmopolitan (39\%).

Os inquiridos quando questionados sobre os temas que mais lhes interessavam, (28\%) referiu o tema "Autoestima". Os temas "Alimentação" e "Saúde" nunca foram mencionados como temas que mais interessam aos leitores. Como segunda opção os inquiridos escolheram a rúbrica o "Privado", que aborda histórias e experiências de vida (18\%).

Os estudantes de moda têm idades compreendidas entre os 21 e os 30 anos $(68 \%)$ e são maioritariamente do sexo feminino $(90 \%)$. Quanto à revista ser ou não uma ferramenta de trabalho, 65\% dos estudantes respondeu que sim e consideram o layout da revista apelativa, e (48\%) referiu que consultavam a revista para conhecer as novas tendências de moda.

Uma percentagem substancial $(45 \%)$ e $(36 \%)$ afirmou que através da revista podiam aceder a diferentes looks e a novidades do mundo da moda. Relativamente às produções 
de moda, (58\%) afirmou que estas assumem um papel de destaque na revista. Contudo, um número muito aproximado de estudantes considera que as produções de moda não têm qualquer destaque na HAPPY Woman (42\%). Quanto à diversificação dos temas ligados à moda, 52\% responderam que consideraram que os temas deveriam ser mais variados, e que deveriam dar um maior destaque às tendências de moda, (13\%).

Quanto aos dados relativos aos conteúdos de moda, segundo os estudantes de comunicação, os estudantes de comunicação situam-se na faixa etária compreendida por indivíduos menores ou iguais a 20 anos (54\%) e entre 21 e 30 anos, $46 \%$. Este grupo caracteriza-se ainda pelo facto de serem apenas do sexo feminino. No que concerne aos conteúdos de moda, as leitoras consideram a sua linguagem muito clara, embora a opção "claro" apareça em número significativo. Podemos ainda destacar o facto da classificação "nada claro" nunca ter sido escolha das inquiridas. E, para finalizar, as estudantes de comunicação foram questionadas sobre uma possível existência de mais rúbricas que abordassem temas ligados à moda na revista HAPPY Woman e (96\%) que respondeu que sim e apenas um indivíduo respondeu que não.

\section{CONClusões}

Os leitores da Happy Woman são na sua maioria do sexo feminino e estudantes de moda.

No que diz respeito à preferência dos leitores, relativamente aos conteúdos abordados verificou-se que a seccão Auto Estima aparece em $1^{\circ}$ lugar e a seção júnior em último.

65\% dos estudantes de moda consideram o layout apelativo e utilizam esta revista como uma ferramenta de trabalho. Embora as produções de moda assumam um papel de destaque, os inquiridos acham que deveria haver mais reportagens que abordassem temas ligados à moda.

De acordo com o que foi aferido através dos resultados da pesquisa, concluímos que, na opinião dos leitores, a HAPPY Woman difunde uma mensagem de moda. De notar que para $96 \%$ dos alunos de comunicação esta mensagem é transmitida, enquanto para os estudantes de moda (71\%) acha que a publicação cumpre este requisito. Apenas uma pequena parte dos inquiridos respondeu que a HAPPY não transmitia uma clara mensagem de moda. No entanto, foram mais os alunos de moda a possuírem tal percepção (29\%).

\section{Agradecimentos}

This work was partly funded by FEDER funds through the Operational Competitiveness Program (COMPETE) and by FCT with the projects PEst-C/CTM/UI0264/2011.
[1] Lipovetsky, G, La Troisième femme: permanence et révolution du feminine, Paris, Gallimard, 1997.

[2] Buittoni D S, Imprensa Feminina, São Paulo, Editora Ática, 1990.

[3] Sullerot, 1966, Evelyne. La presse féminine. Paris: A. Colin, 1963.

[4] Wolf, N, The Beauty Myth: How Images of Beauty Are Used Against Women, Harper Perennial, New York, 1991.

[5] Gama, M, G, “Intervir no corpo para reconfigurar a vida”, Gt 14 - Que pode o corpo. Arte história e moda, 12-15 de setembro de 2010, $6^{\circ}$ Colóquio de moda, ISSN 1982-0941.

[6] Goldenberg, M (Org.) Nu e vestido. Dez antropólogos revelam a cultura do corpo carioca, São Paulo, Record, 2002.

[7] Gama, M, G, Lady Gaga: um corpo além do corpo, 2012, ISSN 2238-9245, II SIEP Consumo: Afetividades e Vínculos, II Seminário Internacional de Estudos e Pesquisas em Consumo, 23 25, São Paulo. pp. 1-7 http://siepconsumo.com.br/2012/pdf/Sess\%C3\%A3o\%20de\%20C omunica\%C3\%A7\%C3\%A3o\%20II/Lady\%20gaga.pdf

[8] Baudrillard, J. A sociedade de consumo. Lisboa: Edições 70, 2005.

[9] Buittoni, D, S. Imprensa feminina. 2a ${ }^{\text {a }}$ Ed. São Paulo: Editora Ática, 1986.

[10] Crane, D, A moda e seu papel social: classe, gênero e identidade das roupas, São Paulo, Editora SENAC, 2006.

[11] Ali, ALI, Fátima, A Arte de editar revistas, São Paulo: Companhia Editora Nacional, 2009

[12] Barthes, R, O sistema da moda, Lisboa, Edições 70, 1999.

[13] Scalzo, M, Jornalismo de Revista, São Paulo, Contexto, 2006.

\section{REFERÊNCIAS}

